\title{
Interação pontas-adjuvantes na estimativa do risco potencial de deriva de pulverizações
}

\author{
Ronaldo P. Madureira ${ }^{1}$, Carlos G. Raetano ${ }^{2}$ \& Jhonatan D. Cavalieri ${ }^{3}$
}

\author{
Palavras-chave: \\ tecnologia de aplicação \\ espectro de gotas \\ polímero vegetal \\ surfactante \\ ester metílico
}

\begin{abstract}
R E S U M O
É crescente a preocupação com os riscos da deriva em pulverizações com produtos fitossanitários e seus efeitos sobre o ambiente, sendo cada vez mais importante a utilização de tecnologias que forneçam maior segurança. Objetivou-se avaliar pontas de pulverização de jato plano inclinado e jato plano com indução de ar empregadas na pulverização com diferentes adjuvantes de uso agrícola na estimativa do risco potencial de deriva por meio dos depósitos e espectro das gotas. Os tratamentos consistiram de quatro soluções combinadas a duas pontas de pulverização. Os depósitos foram medidos em diferentes distâncias e alturas, em túnel de vento. Os indicadores relativos ao espectro de gotas foram: porcentagem do volume de gotas com diâmetro menor ou igual a $100 \mu \mathrm{m}$, diâmetro da mediana volumétrica (DMV) e a amplitude relativa, determinados em um medidor de partículas a laser. A adição do adjuvante polímero vegetal à água propiciou diminuição dos depósitos, redução da porcentagem do volume de gotas com diâmetro menor ou igual a $100 \mu \mathrm{m}$ e DMV maiores, indicando redução do risco potencial de deriva. Depósitos maiores foram obtidos com a ponta de jato plano inclinado sem adição de adjuvantes à calda, representando maior risco potencial de deriva em pulverização.
\end{abstract}

\section{Key words:}

application technology

droplet spectrum

vegetal polymer

surfactant

methyl ester

\section{Interaction spray nozzle-adjuvant to estimate potential risk of spray drift}

\begin{abstract}
A B S T R A C T
There is increasing concern about the risk of pesticide spray drift and their effects on the environment, becoming increasingly important to use spray technologies that provide greater security. This study aimed to evaluate flat angled fan nozzle and the air induction flat fan nozzle combined to different spray adjuvant for agricultural use to estimate the potential risk of spray drift through deposits and spectrum of drops. The treatments were four spray solutions combined with two spray nozzles. Spray deposits were measured at different distances and heights into a wind tunnel. Indicators of droplet spectrum were: percentage of droplets volume smaller than or equal to $100 \mu \mathrm{m}$ of diameter, volume median diameter (VMD), and relative span factor, obtained in a laser particle analyser. The addition of vegetal polymer adjuvant to water resulted in lower levels of spray deposits, reducing the percentage of droplets volume smaller than or equal to $100 \mu \mathrm{m}$ of diameter and showed larger VMD, indicating low potential risk of spray drift. Higher deposit levels were obtained under angled flat fan nozzle without addition of adjuvant to the spray solution, which represents a greater potential risk of spray drift.
\end{abstract}

Protocolo 414.13 - 18/12/2013 • Aprovado em 26/09/2014 • Publicado em 01/02/2015

${ }^{1}$ Departamento de Produção Vegetal, Defesa Fitossanitária/FCA/UNESP, Botucatu, SP. E-mail: ronaldomadureira22@yahoo.com.br (Autor correspondente)

${ }^{2}$ Departamento de Produção Vegetal, Defesa Fitossanitária/FCA/UNESP, Botucatu, SP. E-mail: raetano@fca.unesp.br

${ }^{3}$ Departamento de Produção Vegetal, Defesa Fitossanitária/FCA/UNESP, Botucatu, SP. E-mail: jdcavalieri@gmail.com 


\section{INTRODUÇÃo}

Durante a pulverização dos produtos fitossanitários sobre uma área alvo, quando não é realizada dentro das condições meteorológicas ideais para tal, é inevitável que parte dela seja perdida para o ambiente por deriva. Entende-se por deriva o desvio da trajetória das gotas em relação ao alvo durante e após a pulverização ocasionando perdas do produto (Matthews, 2000).

Na maior parte das vezes atribui-se muita importância ao produto fitossanitário a ser aplicado e pouca à técnica de aplicação (Cunha, 2008). Não basta conhecer o produto a ser aplicado mas é fundamental conhecer também a forma de aplicação para garantir que o produto alcance o alvo de forma eficiente minimizando as perdas por deriva para o ambiente.

As pontas de pulverização são responsáveis pela formação das gotas e por isso determinantes no processo de pulverização e diminuição da deriva (Ferreira et al., 2011).

As pontas com indução de ar representam um avanço maior na direção de reduzir a deriva das pulverizações. Essas pontas promovem a mistura de ar com o líquido de pulverização de modo que as gotas produzidas são maiores do que aquelas obtidas com pontas convencionais de mesma vazão (Boller \& Raetano, 2011). Teoricamente, as pontas de pulverização com certo grau de inclinação a favor do sentido de deslocamento, auxiliam na redução de deriva em razão do lançamento do jato de pulverização sofrer menor interferência da velocidade de deslocamento do pulverizador, diminuindo o lançamento de gotas para um lugar alvo não desejado.

Uma estratégia importante a ser utilizada como forma de diminuir o risco da deriva é a adição de adjuvantes agrícolas junto à calda a ser pulverizada. Algumas pesquisas demonstram o potencial dos adjuvantes na diminuição do risco de deriva das pulverizações de produtos fitossanitários (Iost, 2008; Cunha et al., 2010; Chechetto et al., 2013).

Adjuvante é qualquer substância que, adicionada durante o processo de formulação do produto fitossanitário ou no preparo da calda, facilita a aplicação, reduz perdas e riscos durante o processo e melhora o desempenho do agente químico de controle (Gelmini et al., 2002).

A dificuldade de se estimar a deriva de pulverizações a campo frente às variações climáticas e a falta de normalização no uso de coletores e bioindicadores, tal como de outros fatores a serem controlados durante a pulverização, têm levado pesquisadores (Hoffmann et al., 2008; Nuyttens et al., 2009; Schampheleire et al., 2009; Gandolfo et al., 2012) a realizarem estudos de risco de deriva sob condições controladas em túnel de vento.

A construção e a validação de um túnel de vento para ensaios de estimativa da deriva em pulverizações agrícolas, por Moreira Júnior \& Antuniassi (2010) permitem estimar a distância horizontal percorrida por gotas da pulverização em diversas condições de lançamento e correlacionar a distância horizontal percorrida pela gota com seu diâmetro e com sua velocidade no sentido horizontal.

Diante desta situação objetivou-se, com este trabalho, avaliar o efeito da pulverização empregando pontas de jato plano inclinado e jato plano com indução de ar combinados a diferentes adjuvantes de uso agrícola no risco potencial de deriva em pulverizações realizadas em túnel de vento.

\section{Material e Métodos}

O experimento para avaliação do risco potencial de deriva foi realizado no Laboratório de Máquinas para Pulverização do Núcleo de Ensaio de Máquinas e Pneus Agro-Florestais, Departamento de Engenharia Rural da Faculdade de Ciências Agronômicas/UNESP, Campus de Botucatu, durante o período compreendido entre janeiro e fevereiro de 2013.

O experimento foi conduzido no delineamento inteiramente casualizado, com oito tratamentos e quatro repetições.

Os tratamentos foram distribuídos no esquema fatorial 4 x 2, constituído por quatro tipos de calda ((água; surfactante + água; polímero vegetal + água e éster metílico de óleo de soja + água) combinados a duas pontas de pulverização de energia hidráulica (ponta Hypro ; modelo GRD 12003 (malha do filtro 50 , pressão de $552 \mathrm{kPa}$, vazão de $1,58 \mathrm{~L} \mathrm{~min}^{-1}$ ) jato plano inclinado (posicionado contra o sentido de deslocamento do fluxo de ar) e ponta Jacto ${ }^{\circ}$ modelo JAI 120025, (malha do filtro 50, pressão de $828 \mathrm{kPa}$, vazão de 1,62 $\mathrm{L} \mathrm{min}^{-1}$ ), jato plano simples com indução de ar)). (Tabela 1). As pontas de pulverização e suas respectivas pressões de trabalho foram selecionadas em função das pulverizações realizadas a campo sob altas velocidades de operação $\left(16 \mathrm{~km} \mathrm{~h}^{-1}\right)$.

A seleção dos adjuvantes foi realizada com base na recomendação desses produtos pelos fabricantes, com propriedades de redução da deriva quando adicionados à água. De acordo com Vargas \& Roman (2006) os óleos vegetais retardam, quando adicionados à calda de pulverização, a evaporação das gotas, reduzem a deriva e atuam como espalhante e adeviso das gotas.

Os adjuvantes e seus ingredientes ativos e respectivos grupos químicos, estão descritos na Tabela 2 .

A medição dos depósitos das pulverizações foi realizada em túnel de vento modificado daquele descrito por Moreira Júnior \& Antuniassi (2010).

O túnel de vento é de circuito aberto e a seção de teste fechada com comprimento de 5,3 m, 1,0 m de largura e 0,7 $\mathrm{m}$ de altura, possui um sistema de gavetas móvel que corre sobre trilho e podem ser feitos o movimento de abertura e o fechamento da gaveta para colocação dos alvos coletores (fios de polietileno) de maneira que, ao fechá-la, veda-se a saída do fluxo de ar. O sistema foi dimensionado para fornecer fluxo laminar de ar com velocidade constante de $2,0 \mathrm{~m} \mathrm{~s}^{-1}$.

Tabela 1. Pontas hidráulicas, caldas e concentração dos adjuvantes utilizados para avaliação do potencial risco de deriva

\begin{tabular}{|c|c|c|c|}
\hline Tratamento & Ponta & Calda $^{1}$ & $\begin{array}{l}\text { Concentração do adjuvante } \\
\text { (g ou mL } 100 \mathrm{~L}^{-1} \text { ) }\end{array}$ \\
\hline 1 & JAI 120025 & água & - \\
\hline 2 & JAl 120025 & $\begin{array}{c}\text { água + éster metílico } \\
\text { de óleo de soja }\end{array}$ & $250 \mathrm{~mL}$ \\
\hline 3 & JAI 120025 & $\begin{array}{c}\text { água + polímero } \\
\text { vegetal }\end{array}$ & $60 \mathrm{~g}$ \\
\hline 4 & JAI 120025 & água + surfactante & $100 \mathrm{~mL}$ \\
\hline 5 & GRD 12003 & água & - \\
\hline 6 & GRD 12003 & $\begin{array}{c}\text { água + éster metílico } \\
\text { de óleo de soja }\end{array}$ & $250 \mathrm{~mL}$ \\
\hline 7 & GRD 12003 & $\begin{array}{c}\text { água + polímero } \\
\text { vegetal }\end{array}$ & $60 \mathrm{~g}$ \\
\hline 8 & GRD 12003 & água + surfactante & $100 \mathrm{~mL}$ \\
\hline
\end{tabular}

${ }^{1}$ Em todas as caldas foi adicionado o marcador corante Azul Brilhante $\left(6,0 \mathrm{~g} \mathrm{~L}^{-1}\right)$ 
Tabela 2. Características dos adjuvantes utilizados na calda de pulverização

\begin{tabular}{cccc}
\hline Nome comercial & Composição & Formulação & Classificação $^{1}$ \\
Aureo ${ }^{\circledR}$ & Éster metílico de óleo de soja $(72,0 \% \mathrm{~m} / \mathrm{v})$ & Concentrado emulsionável & Adjuvante \\
Define $^{\circledR}$ & Polímero vegetal & Concentrado solúvel & Adjuvante \\
Silwet L-77 ${ }^{\circledast}$ & Copolímero de poliéter e silicone $(100 \% \mathrm{~m} / \mathrm{v})$ & Concentrado dispersível & Espalhante adesivo \\
\hline
\end{tabular}

'Brasil (2013)

O sistema de pulverização do túnel de vento é constituído por um tanque de aço inox com capacidade de $15 \mathrm{~L}$ no qual foram armazenadas e pressurizadas as caldas das pulverizações. A pressurização do sistema foi realizada por cilindro de gás comprimido $\left(\mathrm{CO}_{2}\right)$. Em um orifício localizado na parte superior do túnel foi colocado um suporte, no qual foi acoplado o bico de pulverização para posicioná-lo corretamente no fluxo de ar mantendo a ponta de pulverização a uma altura de $0,50 \mathrm{~m}$ em relação ao piso do túnel de vento.

As caldas foram preparadas minutos antes da pulverização. Água destilada foi utilizada como veículo de diluição das caldas com adição do marcador corante Azul Brilhante, na concentração $0,6 \% \mathrm{~m} \mathrm{v}^{-1}\left(6 \mathrm{~g} \mathrm{~L}^{-1}\right)$ e adjuvante específico do respectivo tratamento.

Alvos artificiais constituídos por fios de polietileno com 2,0 mm de diâmetro e 1,0 m de comprimento foram utilizados para a coleta dos depósitos da pulverização. Os fios foram posicionados horizontalmente e perpendicularmente ao comprimento do túnel por meio de gavetas móveis as quais permitiram fixá-los e removê-los. Esses alvos foram posicionados a 1,5;2,0;2,5 e 3,0 m de distância em relação à ponta de pulverização. Nas respectivas distâncias os fios foram fixados a 0,$10 ; 0,20$ e $0,30 \mathrm{~m}$ de altura com relação ao piso do túnel. Desta forma, cada ensaio foi composto por 12 fios coletores por repetição, com quatro repetições, totalizando 48 fios coletores para serem analisados por tratamento adaptado de Moreira Júnior \& Antuniassi (2010).

O tempo de pulverização por repetição foi $10 \mathrm{~s}$, determinado com o auxílio de cronômetro digital. Após o término da pulverização o ventilador foi mantido ligado por um minuto e após o desligamento se aguardaram cinco minutos para a total estabilização do ambiente dentro da secção de testes e deposição das gotas nos fios de polietileno.

Durante a pulverização de cada repetição foi realizado o monitoramento das condições meteorológicas, sempre preconizando temperatura abaixo de $30^{\circ} \mathrm{C}$ e umidade relativa do ar acima de 50\%. De acordo com Gandolfo \& Antuniassi (2005) as condições meteorológicas ideais são ótimas quando a temperatura se encontra entre 14 e $30{ }^{\circ} \mathrm{C}$; para a umidade relativa o valor mínimo recomendado é de $50 \%$ e para o vento, valores compreendidos entre 4 e $10 \mathrm{~km} \mathrm{~h}^{-1}$.

Os fios de polietileno foram retirados e acondicionados dentro de sacos plásticos identificados com o respectivo tratamento e posicionamento no interior do túnel de vento. Ao final da pulverização correspondente a cada tratamento foi recolhida uma amostra de $300 \mathrm{~mL}$ da calda e utilizada na confecção da curva de calibração padrão de linearidade crescente do marcador Azul Brilhante.

Ao término das pulverizações as amostras com os alvos coletados foram levadas ao laboratório para extração do marcador. Aos sacos plásticos contendo os fios de polietileno foram adicionados $15 \mathrm{~mL}$ de água destilada agitando-os manualmente por $30 \mathrm{~s}$ para extração do marcador. O líquido resultante da lavagem do fio foi acondicionado em frascos plásticos com capacidade de $100 \mathrm{~mL}$.

A quantificação do marcador nas soluções de lavagem dos alvos foi feita por espectrofotômetro Shimadzu UVVIS 1601 PC equipado com filtro no comprimento de onda de 630 nanômetros (nm). As leituras do marcador Azul Brilhante foram realizadas em absorbância e transformadas em $\mathrm{mg} \mathrm{L}^{-1}$ por intermédio de confecções de curvas-padrão de linearidade, com base na concentração do marcador na calda coletada ao final de cada tratamento, pelas respectivas equações: $\mathrm{y}=0,1309 \mathrm{x}-0,0025, \mathrm{y}=0,1225 \mathrm{x}-0,002, \mathrm{y}=$ $0,1119 \mathrm{x}-0,0042$ e $\mathrm{y}=0,1404 \mathrm{x}-0,0081$ para as caldas contendo água, adjuvantes éster metílico, polímero vegetal e surfactante. Os valores dos depósitos de calda em todos os fios de polietileno de cada tratamento, foram transformados em uma porcentagem de deriva representando, assim, o potencial risco de deriva que cada tratamento pode gerar.

Os valores das médias dos depósitos foram comparados pela análise dos intervalos de confiança (IC) e considerados estatisticamente diferentes quando não houve sobreposição dos intervalos de confiança a 95\% de significância.

Em complemento à avaliação de deriva das pulverizações realizadas em túnel de vento, mediu-se o espectro de gotas produzido pelas mesmas pontas combinadas aos adjuvantes, conforme descrito anteriormente. As avaliações foram feitas no Laboratório de Análise do Tamanho de Partícula pertencente ao Departamento de Fitossanidade da Faculdade de Ciências Agronômicas e Veterinárias/UNESP, Campus de Jaboticabal, em Fevereiro de 2012; para isto, adotou-se o delineamento experimental inteiramente casualizado com oito tratamentos distribuídos no esquema fatorial 2 × 4 (duas pontas e quatro caldas). Para cada modelo de ponta de pulverização usadas no túnel de vento foram utilizados três exemplares de cada modelo de ponta de pulverização e para cada exemplar foram feitas quatro leituras do espectro de gotas totalizando 12 repetições por tratamento.

O espectro de gotas foi avaliado em medidor de partículas a laser, modelo Mastersizer, da Malvern Instruments Ltd. Nas avaliações cada ponta hidráulica foi instalada a $0,50 \mathrm{~m}$ do feixe de laser e movimentada $45^{\circ}$ para a direita, de modo que as gotas aspergidas interceptassem transversalmente o laser, possibilitando a amostragem de toda a faixa do jato aspergido pela ponta de pulverização.

O volume de calda preparado minutos antes da análise, foi de $15 \mathrm{~L}$ para os respectivos tratamentos, seguindo as concentrações recomendadas dos adjuvantes pelos fabricantes. A diluição dos adjuvantes foi feita utilizando-se água do sistema público de abastecimento.

As condições ambientais foram monitoradas durante a avaliação com o auxílio de um termo-higrômetro digital, temperatura $\left(25 \pm 2^{\circ} \mathrm{C}\right)$ e umidade relativa $(76 \pm 5 \%)$. 
Os parâmetros da análise do espectro das gotas foram: porcentagem de volume de gotas com diâmetro menores ou iguais a $100 \mu \mathrm{m}$ (porcentagem de gotas $\leq 100 \mu \mathrm{m}$ ), o diâmetro da mediana volumétrica (DMV) e a amplitude relativa (AR). Os dados obtidos foram submetidos à análise de variância e as médias comparadas pelo teste de Tukey $(\mathrm{p}<0,05)$.

\section{Resultados e Discussão}

Os valores médios dos depósitos das caldas de pulverizações do marcador em soluções aquosas associadas ou não aos adjuvantes à base de éster metílico, polímero vegetal e surfactante com as pontas de jato plano inclinado e jato plano com indução de ar, nos fios de polietileno, estão expressos em porcentagem de deriva (Figura 1).

Com a ponta de jato plano inclinada todos os adjuvantes proporcionaram diminuição no valor médio de deriva em comparação com o tratamento controle (água). Esses resultados corroboram com aqueles obtidos por Oliveira (2011) que constatou níveis de deriva menores com a adição de polímeros em soluções aquosas quando comparado a outros adjuvantes.

A viscosidade estensional (viscosidade de alongamento) do líquido tende a resistir ao alongamento porém a viscosidade de cisalhamento de um líquido é obtida pela viscosidade de corte. À medida que a viscosidade de corte é reduzida pulverizações com gotas mais grossas são produzidas. A adição de polímeros à calda de pulverização tende a provocar aumento da viscosidade estensional inicial e pode diminuir a viscosidade de cisalhamento (McMullan, 2000). Alterando esses dois fatores, produzirá uma pulverização com gotas mais grossas, com diâmetro da mediana volumétrica (DMV) maior e menor fração de gotas suscetíveis à deriva.

Apesar de o surfactante siliconado Silwet L-77 ser eficiente na redução da tensão superficial de soluções aquosas (Mendonça et al., 1999; Montório et al., 2005), a adição deste produto reduziu o percentual de deriva em relação à água.

Cunha \& Alves (2009) argumentam, estudando as propriedades físico-químicas de caldas de pulverização com adjuvantes, que a elevação da viscosidade da calda com adjuvantes está associada à geração de gotas de pulverização maiores e, portanto, com diminuição do risco potencial de deriva de uma aplicação.

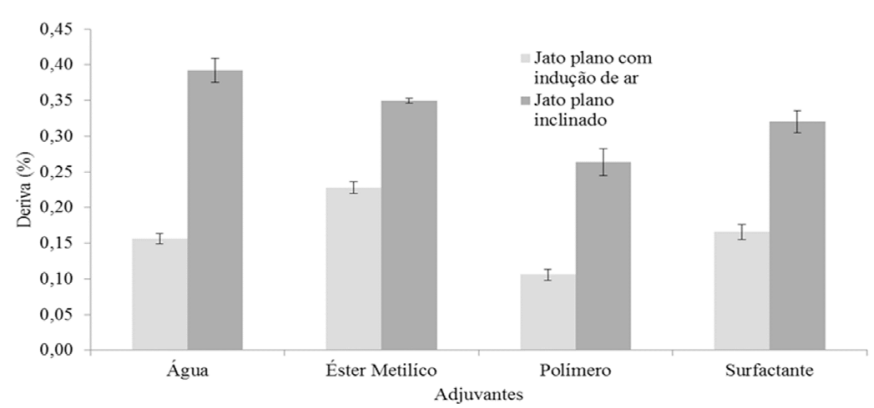

Figura 1. Valores médios de porcentagem de deposição de calda de pulverização nos fios de polietileno expressos em porcentagem de deriva (médias \pm IC95\%) para as diferentes caldas de pulverização contendo os adjuvantes utilizando-se diferentes pontas de pulverização de jato plano
Quanto à pulverização com a ponta de jato plano com indução de ar, somente o tratamento acrescido do adjuvante à base de polímero vegetal apresentou redução significativa da porcentagem de deriva em comparação com os demais tratamentos.

A maior porcentagem de depósitos da pulverização com a ponta de jato plano com indução de ar e solução contendo éster metílico está relacionada, provavelmente, à interação de três fatores, em que o primeiro está relacionado à maior pressão de trabalho com esta ponta $(828 \mathrm{kPa})$, segundo a viscosidade de alongamento da solução contendo o adjuvante e o terceiro à viscosidade de cisalhamento da calda.

A interação líquido/ar no interior das pontas com indução de ar deve ser considerada, o que pode torná-la mais sensível às mudanças nas propriedades físicas da calda embora seu comportamento nem sempre siga o das pontas hidráulicas convencionais (Miller \& Butler-Ellis, 2000).

Os resultados obtidos no presente trabalho corroboram com aqueles encontrados por Chechetto et al. (2013) os quais concluíram, avaliando a deriva em túnel de vento, que a ponta com indução de ar proporcionou menores valores de porcentagem de deriva em comparação a outros modelos de pontas de pulverização.

Pela análise de variância verifica-se que houve efeito de adjuvantes e ponta de pulverização sobre o DMV das gotas de pulverização, sobre a porcentagem de volume de gotas com diâmetros menores ou iguais a $100 \mu \mathrm{m}$ (porcentagem de gotas $\leq 100 \mu \mathrm{m}$ ), bem como sobre a amplitude relativa (AR). Também é notória a interação dos fatores adjuvante e ponta de pulverização em todos os parâmetros de avaliação do espectro de gotas (Tabela 3).

A calda contendo o polímero vegetal apresentou DMV superior em comparação àquelas contendo éster metílico, surfactante e a própria água. O DMV foi aumentado em 33\% quando adicionado o adjuvante à base de polímero vegetal à água.

O desempenho do mesmo polímero vegetal sobre a porcentagem de gotas $\leq 100 \mu \mathrm{m}$ e DMV foi avaliado por Oliveira (2011). O autor encontrou menor porcentagem de gotas $\leq 100 \mu \mathrm{m}$ e maior valor do DMV dentre os adjuvantes estudados, estando em conformidade com os resultados obtidos neste trabalho.

Ruiter et al. (2003) e Spanoghe (2005), também constataram aumento no DMV das gotas quando adicionado polímero junto à calda de pulverização.

Devido à maior porcentagem do volume de gotas com diâmetro menores ou iguais a $100 \mu \mathrm{m}(\%$ gotas $\leq 100 \mu \mathrm{m})$ e à diminuição do DMV para o tratamento realizado com a ponta de jato plano com indução de ar pulverizando a calda com o

Tabela 3. Análise da variância com os valores de F para porcentagem de volume de gotas com diâmetros menores ou iguais a $100 \mu \mathrm{m}$ (\% gotas $\leq 100 \mu \mathrm{m})$, diâmetro mediano volumétrico (DMV) e amplitude relativa (AR)

\begin{tabular}{|c|c|c|c|c|}
\hline $\begin{array}{c}\text { Fontes } \\
\text { de variação }\end{array}$ & GL & $\% \leq 100 \mu \mathrm{m}$ & DMV & AR \\
\hline Adjuvantes & 3 & $29,99 * \star$ & $60,40 \star \star$ & $57,49 * \star$ \\
\hline Pontas & 1 & $58,43^{\star *}$ & $232,61^{* *}$ & $391,54^{\star *}$ \\
\hline Adjuvantes $\mathrm{x}$ Pontas & 3 & $4,97^{\star}$ & 11,09 ** & $60,65^{\star \star}$ \\
\hline
\end{tabular}


adjuvante éster metílico é possível explicar os maiores níveis de porcentagem de deriva encontrado nas avaliações realizadas no túnel de vento.

É provável que a calda contendo o adjuvante éster metílico submetida à pressão de trabalho maior pela ponta jato plano com indução de ar, não tenha resistido à tensão de alongamento, diminuindo a viscosidade de alongamento e aumentando a velocidade de corte da calda produzindo maior porcentagem de gotas $\leq 100 \mu \mathrm{m}$ e diminuição do $\mathrm{DMV}$, resultando no aumento do risco potencial de deriva em comparação com os demais tratamentos.

O DMV das gotas com a ponta de jato plano inclinado foi significativamente maior que aquele obtido com a ponta jato plano com indução de ar. O desenho da ponta jato plano inclinado e a menor pressão de trabalho contribuíram, sem dúvida, para o aumento do DMV das gotas da pulverização.

A água e a solução aquosa acrescida do polímero vegetal, apresentaram valores de amplitude relativa maiores, diferindo dos demais valores obtidos com outras soluções; na prática, isto representa menor uniformidade do espectro de gotas desses tratamentos em comparação àqueles contendo surfactante e éster metílico em água enquanto para o fator pontas de pulverização a ponta jato plano inclinado obteve o maior valor de amplitude relativa o qual foi estatisticamente superior ao obtido pela ponta jato plano com indução de ar.

Quanto maior a amplitude relativa menor a uniformidade do espectro das gotas da pulverização e, consequentemente, menor também é a qualidade da pulverização; assim, a ponta jato plano com indução de ar produz espectro de gotas mais uniforme em comparação à ponta jato plano inclinado.

A distribuição volumétrica e o espectro de gotas de pontas de pulverização de baixa deriva foram avaliados por Viana et al. (2010). Os autores constataram que as pontas com indução de ar produziram espectro de gotas mais uniforme em comparação aos outros modelos de pontas.

A análise do fator ponta dentro de cada adjuvante revela que a porcentagem de gotas $\leq 100 \mu \mathrm{m}$ com a ponta jato plano inclinado foi superior em comparação à obtida com a ponta jato plano com indução de ar, para todas as soluções, exceto na solução contendo éster metílico (Tabela 4).

Com a ponta de jato plano inclinado e somente água, obteve-se o maior valor da porcentagem de gotas $\leq 100$ $\mu \mathrm{m}$, e com o polímero vegetal foi obtido valor menor para este parâmetro de análise do espectro de gotas, dentre os adjuvantes. Para a ponta de jato plano com indução de ar, a solução contendo polímero vegetal apresenta valor menor da porcentagem de gotas $\leq 100 \mu \mathrm{m}$, diferindo dos valores obtidos com as demais soluções, que não diferiram entre si.

Pode-se observar, pela análise do fator adjuvante dentro de cada ponta, que na ponta de jato plano inclinado o DMV das gotas com surfactante não diferiu do adjuvante à base de éster metílico porém o DMV das gotas com o acréscimo do polímero vegetal à água diferiu daquele obtido sem adjuvante e das soluções acrescidas do surfactante e éster metílico (Tabela 4).

Comparando o desdobramento da interação adjuvante versus ponta para a porcentagem de gotas $\leq 100 \mu \mathrm{m}$ e para o DMV, tem-se uma relação inversamente proporcional entre esses parâmetros de avaliação do espectro das gotas. Iost (2008) verificou o mesmo comportamento entre a porcentagem de gotas $\leq 100 \mu \mathrm{m}$ e DMV, concluindo que quanto menor a porcentagem do volume de gotas menores que $100 \mu \mathrm{m}$, menores também são as porcentagens de depósito (deriva). Ocorreram diminuição do DMV e aumento da porcentagem de gotas $\leq 100 \mu \mathrm{m}$ para soluções acrescidas dos adjuvantes à base de surfactante e éster metílico para a ponta de jato plano com indução de ar. Os valores de DMV foram reduzidos em 3\% com surfactante e em $10 \%$ com éster metílico em comparação com o tratamento contendo apenas água (controle). Quanto à porcentagem das gotas $\leq 100 \mu \mathrm{m}$, o adjuvante éster metílico aumentou em $12 \%$ quando comparado à água.

Esses resultados corroboram com os obtidos por Cunha et al. (2010) cuja adição de um óleo vegetal à calda proporcionou redução do DMV e aumento da porcentagem de gotas $\leq 100$ $\mu \mathrm{m}$ para ambas as pontas de jato plano defletor TTI 10002 (indução de ar) e TT 11002 em comparação com a calda contendo apenas água.

Os valores de amplitude relativa no desdobramento do fator adjuvantes dentro de pontas foram significativamente maiores apenas com água para a ponta de jato plano inclinado e solução aquosa com polímero vegetal para a ponta de jato plano com indução de ar, implicando em menor uniformidade no espectro de gotas com a água e polímero vegetal quando pulverizados, respectivamente, pelas pontas de jato plano inclinado e de jato plano com indução de ar. As soluções com surfactante e éster

Tabela 4. Desdobramento da interação ponta versus adjuvante para a porcentagem do volume de gotas com diâmetros menores ou iguais a $100 \mu \mathrm{m}$ (\% gotas $\leq 100 \mu \mathrm{m})$, diâmetros de gotas a $50 \%$ do volume acumulado (Dv 0,5) equivalente ao DMV e amplitude relativa (AR) associados a diferentes caldas e pontas de jato plano inclinado e jato plano com indução de ar

\begin{tabular}{|c|c|c|c|c|c|}
\hline Pontas & Água & Surfactante & Éster metílico & Polímero vegetal & DMS \\
\hline & & & $\% \leq 100 \mu \mathrm{m}$ & & \\
\hline Jato plano inclinado & $15,25 \mathrm{aA}$ & $11,86 \mathrm{aB}$ & $12,66 \mathrm{aB}$ & $9,27 \mathrm{aC}$ & 2,24 \\
\hline Jato plano com indução de ar & $9,71 \mathrm{bA}$ & $9,68 \mathrm{bA}$ & $11,11 \mathrm{aA}$ & $6,05 \mathrm{bB}$ & 2,24 \\
\hline \multirow[t]{2}{*}{ DMS } & 1,66 & 1,66 & 1,66 & 1,66 & \\
\hline & & & DMV & & \\
\hline Jato plano inclinado & $226,31 \mathrm{aA}$ & $258,48 \mathrm{aB}$ & $267,35 \mathrm{aB}$ & $301,55 \mathrm{aC}$ & 22,93 \\
\hline Jato plano com indução de ar & $192,68 \mathrm{bA}$ & $186,11 \mathrm{bA}$ & $174,40 \mathrm{bA}$ & $256,02 \mathrm{bB}$ & 22,93 \\
\hline \multirow[t]{2}{*}{ DMS } & 16,99 & 16,99 & 16,99 & 16,99 & \\
\hline & & & (AR) & & \\
\hline Jato plano inclinado & $2,02 \mathrm{aA}$ & $1,78 \mathrm{aB}$ & $1,77 \mathrm{aB}$ & $1,75 \mathrm{aB}$ & 0,11 \\
\hline Jato plano com indução de ar & $1,46 \mathrm{bA}$ & $1,29 \mathrm{bB}$ & $1,20 \mathrm{bB}$ & $1,82 \mathrm{aC}$ & 0,11 \\
\hline DMS & 0,08 & 0,08 & 0,08 & 0,08 & \\
\hline
\end{tabular}

Médias seguidas de mesma letra, minúscula na coluna e maiúscula na linha, não diferem entre si pelo teste de Tukey $(p<0,05)$ 
metílico apresentaram valores intermediários de amplitude relativa e não diferiram entre si.

\section{Conclusões}

1. A ponta de pulverização de jato plano com indução de ar modelo JAI 120025 com a pressão de trabalho de $828 \mathrm{kPa}$ obtém menor diâmetro da mediana volumétrica, menor porcentagem de gotas $\leq 100 \mu \mathrm{m}$, menor risco potencial de deriva e espectro de gotas mais uniforme quando comparada com a ponta de jato plano inclinado modelo GRD 12003 a $552 \mathrm{kPa}$.

2. O risco potencial de deriva com a ponta de jato plano inclinado é minimizado com a adição dos adjuvantes à água.

3. Somente o adjuvante polímero vegetal minimiza o risco potencial de deriva para a ponta de jato plano com indução de ar.

4. Dos adjuvantes, o polímero vegetal é mais eficiente na redução da deriva em pulverização.

\section{Agradecimentos}

À Coordenação de Aperfeiçoamento de Pessoal de Nível Superior (CAPES) pelo apoio concedido.

\section{Literatura Citada}

Boller, W.; Raetano, C. G. Bicos e pontas de pulverização de energia hidráulica, regulagem e calibração de pulverizadores de barra. In: Antuniassi, U. R.; Boller, W. (Org.) Tecnologia de aplicação para culturas anuais. Passo Fundo: Aldeia Norte; Botucatu: FEPAF, 2011, p.51-80.

Brasil. Ministério da Agricultura, Pecuária e Abastecimento. 2013 $<$ http://agrofit.agricultura.gov.br/agrofit_cons/principal_agrofit_ cons> 20 Ago 2013.

Chechetto, R. G.; Antuniassi, U. R.; Mota, A. A. B.; Carvalho, F. K.; Silva, A. C. A.; Vilela C. M. Influência de pontas de pulverização e adjuvantes no potencial de redução de deriva em túnel de vento. Semina: Ciências Agrárias, v.34, p.37-46, 2013. http:// dx.doi.org/10.5433/1679-0359.2013v34n1p37

Cunha, J. P. A. R. Simulação da deriva de agrotóxicos em diferentes condições de pulverização. Ciência e Agrotecnologia, v.32, p.16161621, 2008. http://dx.doi.org/10.1590/S1413-70542008000500039

Cunha, J. P. A. R.; Alves, G. S. Características físico-químicas de soluções aquosas com adjuvantes de uso agrícola. Interciência, v.34, p.655-659, 2009.

Cunha, J. P. A. R.; Bueno, M. R.; Ferreira, M. C. Espectro de gotas de pontas de pulverização com adjuvantes de uso agrícola. Planta Daninha, v.28, p.1153-1158, 2010. http://dx.doi.org/10.1590/ S0100-83582010000500023

Ferreira, M. C.; Lohmann, T. R.; Campos, A. P.; Viel, S. R.; Figueiredo, A. Distribuição volumétrica e diâmetro de gotas de pontas de pulverização de energia hidráulica para controle de corda-deviola. Planta Daninha, v.29, p.697-705, 2011. http://dx.doi. org/10.1590/S0100-83582011000300024

Gandolfo, M. A.; Antuniassi, U. R. Ar na pulverização. Cultivar Máquinas, v.3, p.12-14. 2005.

Gandolfo M. A.; Moraes, E. D.; Gandolfo, U. D.; Osipe, J. B.; Rodrigues E. B.; Osipe, R. Potencial de deriva da mistura de 2,4 D com glyphosate. Revista Brasileira de Herbicidas, v.11, p.332-338, 2012. http://dx.doi.org/10.7824/rbh.v11i3.192
Gelmini, G. A.; Pelegrinetti, J. R.; Castaneira, L. C. Agrotóxicos e afins - Coletânea da legislação. Tomo IV. Campinas: Coordenadoria de Defesa Agropecuária, 2002. 126p.

Hoffmann, W. C.; Hewitt, A. J.; Ross, J. B.; Bagley, W. E.; Martin, D. E.; Fritz, B. K. Spray adjuvant effects on droplet size spectra measured by three laser-based systems in a high-speed wind tunnel. Journal of ASTM International, v.5, p.1-9, 2008. http:// dx.doi.org/10.1520/JAI101233

Iost, C. A. R. Efeito de adjuvantes nas propriedades físico-químicas da água e na redução de deriva em pulverizações sobre diferentes espécies de plantas daninhas. Botucatu: FCA/UNESP, 2008. 63p. Dissertação Mestrado

Matthews, G. A. Pesticide application methods. 3.ed. London: Balckwell, 2000. 432p. http://dx.doi.org/10.1002/9780470760130

McMullan, P. M. Utility adjuvants. Weed Technology, v.14, p.792797, 2000. http://dx.doi.org/10.1614/0890-037X(2000)014[0792: UA]2.0.CO;2

Mendonça, C. G. De; Velini, E. D.; Martins, D.; Mendonça, C. G. de. Efeitos de surfatantes sobre a tensão superficial e a área de molhamento de soluções de glifosato sobre folhas de tiririca. Planta Daninha, v.17, p.355-365, 1999.

Montório, G. A.: Velini, E. D.; Maciel, C. D. G.; Montório, T. Eficiência dos surfatantes de uso agrícola na redução da tensão superficial. Revista Brasileira de Herbicidas, v.2, p.8-22, 2005.

Moreira Junior, O.; Antuniassi, U. R. Construção e validação de um túnel de vento para ensaios de estimativa da deriva em pulverizações agrícolas. Revista Energia na Agricultura, v.26, p.118-136, 2010.

Miller, P. C. H.; Butler-Ellis, M. C. Effects of formulation on spray nozzle performance for applications from ground-based boom sprayers. Crop Protection, v.19, p.609-615, 2000. http://dx.doi. org/10.1016/S0261-2194(00)00080-6

Nuyttens, D.; Taylor, W. A.; Schampleleire, M. de; Verboven, P.; Dekeyser, D. Influence of nozzle type and size on drift potential by means of different wind tunnel evaluation methods. Biossystems Engineering, v.109, p.271-280, 2009. http://dx.doi.org/10.1016/j. biosystemseng.2009.04.001

Oliveira, R. B. Caracterização funcional de adjuvantes em soluções aquosas. Botucatu: FCA/UNESP, 2011. 134p. Tese Doutorado

Ruiter, H. de; Mol, H. G. J.; Vlieger, J. J. de; Zande, J. C. van de. Influence of adjuvants on the emission of pesticides to the atmosphere. Review: Methodology and perspectives. BCPC Internat Cong. Crop Science and Technology, v.1, p.513-518, 2003.

Schampheleire, M.; Nuyttens, D.; Baetens, K.; Cornelis, W.; Gabriels, D.; Spanoghe, P. Effects on pesticide spray drift of the physicochemical properties of the spray liquid. Precision Agriculture, v.10, p.409-420, 2009. http://dx.doi.org/10.1007/ s11119-008-9089-6

Spanoghe, P. Effect van additieven en adjuvantia op de efficiëntie van de spuittoepassing van gewasbeschermingsmiddelen. UGhent, 2005. 301p. Thesis PhD

Vargas, L.; Roman, E. S. Conceitos e aplicações dos adjuvantes. Passo Fundo: Embrapa Trigo, 2006. 10p. http://www.cnpt.embrapa.br/ biblio/do/p_do56.htm. 20 Dez. 2006.

Viana, R. G.; Ferreira, L. R.; Ferreira, M. C.; Teixeira, M. M.; Rosell, J. R.; Tuffi Santos, L. D.; Machado, A. F. L. Distribuição volumétrica e espectro de gotas de pontas de pulverização de baixa deriva. Planta Daninha, v.28, p.439-446, 2010. http://dx.doi.org/10.1590/S010083582010000200024 